\title{
Economic-based dynamic control of top-lighting and inter- lighting for greenhouse
}

\author{
Yuanxv Wang, Lihong Xu and Ruihua Wei \\ College of Electronics and Information Engineering, Tongji University, Shanghai, P.R. China
}

\begin{abstract}
Summary
The main objective of supplemental lighting is to increase the economic benefits of the grower by means of finding a trade-off between the improvement of crop yield and the electricity consumption. However, studies attempted to optimize supplemental lighting control based on the economic benefits are scant. The aim of this study was to assess the influence of dynamic control of top-lighting and inter-lighting on electricity consumption and yield of tomato. An economic benefit objective function of the supplemental lighting was established. Two dynamic control algorithms were proposed, and actual greenhouse climate data was used to evaluate the effectiveness of these algorithms. The results show that compared with threshold control, dynamic control of top-lighting and interlighting can reduce electricity consumption and increase profits. It can be concluded that inefficient supplemental lighting can be avoided by using these dynamic control algorithms.
\end{abstract}

Keywords

economic benefit, model-based optimization, objective function, supplemental lighting control

\section{Introduction}

Supplemental lighting is routinely used to avoid light insufficiency in greenhouses (Heuvelink et al., 2006). However, the use of supplemental lighting also causes a significant increase in electricity consumption. The application of light-emitting diodes (LEDs) in greenhouse allows reduction of operational cost due to the high energy efficiency, low maintenance cost and longevity (Morrow, 2008; Singh et al., 2015). In addition, LEDs are suitable for inter-lighting because of low radiated heat (Hogewoning et al., 2007). Inter-lighting is to place artificial light within the canopy to illuminate the lower leaves of the crop. Previous studies have found that inter-lighting improves photosynthetic capacity of lower canopy leaves (Tewolde et al., 2016; Jiang et al., 2017), leading to an increase in yield (Koivisto and Hovi-Pekkanen, 2008; Pepin et al., 2014; Guo et al., 2016). Another attractive feature of LED is the possibility of full control of light intensity. Lower light intensity means lower electricity consumption. Numerous experiments have found that dynamic control of supplemental lighting intensity can reduce electricity consumption (Pinho et al., 2013; Schwend et al., 2016; Van Iersel and Gianino, 2017).

Although many studies have investigated inter-lighting, dynamic control of supplemental lighting intensity and dynamic optimization of supplemental lighting (Heuvelink

\section{Significance of this study}

What is already known on this subject?

- Combination of top-lighting and inter-lighting increased the yield more than top-lighting alone with the same amount of electricity consumption.

What are the new findings?

- Compared with threshold control, dynamic control of top-lighting and inter-lighting can improve economic benefits.

What is the expected impact on horticulture?

- The results provide a new idea about the control method of supplemental lighting, and will promote the application of supplemental lighting techniques in actual greenhouse production.

and Challa, 1989), there is no comprehensive study which attempts to optimize top-lighting and inter-lighting based on economic benefits. Most of the studies controlled supplemental lighting based on outdoor global radiation (threshold control). However, photosynthetic rate depends on several factors. For example, the relative effect of light on photosynthesis is greater at lower light levels (Van Iersel and Gianino, 2017), at higher $\mathrm{CO}_{2}$ concentration (Bergstrand et al., 2016), at higher temperature. Moreover, the economic benefit of supplemental lighting depends on the margin between the increase in crop value and the cost of supplemental lighting. Economic optimum supplemental lighting intensity depends on several factors: the effect of supplemental lighting on the photosynthesis, the partitioning to fruit, and the price of fruit, as well as the electricity consumption of supplemental lighting, and the electricity price.

Therefore, we hypothesized that, compared with threshold control, economic-based dynamic control of top-lighting and inter-lighting will reduce electricity consumption and improve the economic benefit. The objective of this study was to assess the influence of dynamic control of top-lighting and inter-lighting on electricity consumption and yield of tomato. Finding the optimal solution by experiment is not feasible due to high financial and time investment. Thus, experiments were conducted by simulation.

\section{Materials and methods}

\section{Leaf photosynthesis model}

Leaf photosynthesis model used in the simulation is that of Vanthoor et al. (2011), which is a modified version of the model of Farquhar et al. (1980). Leaf photosynthetic rate $\mathrm{P}_{\text {leaf }}$ $\left(\mu \mathrm{mol} \mathrm{s}^{-1} \mathrm{~m}^{-2}\right)$ is given by: 


$$
\mathrm{P}_{\text {leaf }}=\frac{\mathrm{J}\left(\mathrm{C}_{\mathrm{i}}-\Gamma^{*}\right)}{4\left(\mathrm{C}_{\mathrm{i}}+\Gamma^{*}\right)}-R_{d}
$$

where $\mathrm{C}_{\mathrm{i}}$ is the intercellular $\mathrm{CO}_{2}$ concentration $\left(\mu \mathrm{mol} \mathrm{mol}^{-1}\right)$, $\Gamma^{*}$ is $\mathrm{CO}_{2}$ compensation point $\left(\mu \mathrm{mol} \mathrm{mol}^{-1}\right), \mathrm{R}_{\mathrm{d}}$ is dark respiration rate $\left(\mu \mathrm{mol} \mathrm{s}^{-1} \mathrm{~m}^{-2}\right)$ and $\mathrm{J}$ is the electron transport rate $\left(\mu \mathrm{mol} \mathrm{s}^{-1} \mathrm{~m}^{-2}\right)$. Electron transport rate is calculated as:

$$
J=\frac{\alpha I+J_{\max }-\sqrt{\left(\alpha I+J_{\max }\right)^{2}+4 \theta \alpha I J_{\max }}}{2 \theta}
$$

where $\alpha$ is the conversion factor from photons to electrons $\left(0.376 \mu \mathrm{mol} \mu \mathrm{mol}^{-1}\right), \theta$ is the degree of curvature of the electron transport rate $(0.3), \mathrm{J}_{\max }$ is the potential electron transport rate $\left(\mu \mathrm{mol} \mathrm{s}{ }^{-1} \mathrm{~m}^{-2}\right)$ and $\mathrm{I}$ is the absorbed light $(\mu \mathrm{mol}$ $\mathrm{s}^{-1} \mathrm{~m}^{-2}$ ). The potential electron transport rate depends on leaf temperature:

$$
\begin{array}{r}
J_{\max }=J_{\max }\left(25^{\circ} C\right) \exp \left(\frac{H_{a}\left(T_{\text {leaf }}-25\right)}{298.15\left(T_{\text {leaf }}+273.15\right) R}\right) \\
\times \frac{1+\exp \left(\frac{298.15 S-H_{d}}{298.15 R}\right)}{1+\exp \left(\frac{S\left(T_{\text {leaf }}+273.15\right)-H_{d}}{R\left(T_{\text {leaf }}+273.15\right)}\right)}
\end{array}
$$

where $\mathrm{J}_{\max }\left(25^{\circ} \mathrm{C}\right)$ is the potential electron transport rate at $25^{\circ} \mathrm{C}\left(\mu \mathrm{mol} \mathrm{s}^{-1} \mathrm{~m}^{-2}\right), \mathrm{H}_{\mathrm{a}}$ is the activation energy $\left(60,185 \mathrm{~J} \mathrm{~mol}^{-}\right.$ $\left.{ }^{1}\right), \mathrm{T}_{\text {leaf }}$ is the leaf temperature $\left({ }^{\circ} \mathrm{C}\right), \mathrm{R}$ is the molar gas constant $\left(8.137 \mathrm{~J} \mathrm{~mol}^{-1} \mathrm{~K}^{-1}\right), \mathrm{S}$ is the entropy term $\left(650 \mathrm{~J} \mathrm{~mol}^{-1} \mathrm{~K}^{-1}\right)$, and $\mathrm{H}_{\mathrm{d}}$ is the deactivation energy $\left(201,000 \mathrm{~J} \mathrm{~mol}^{-1}\right)$. Intercellular $\mathrm{CO}_{2}$ concentration is assumed to be a fixed fraction of the $\mathrm{CO}_{2}$-concentration in the greenhouse air:

$$
C_{i}=\eta_{\text {Air_-Stom }} C O_{2 A i r}
$$

where $\eta_{\text {Air_stom }}(0.67)$ is conversion coefficient. $\mathrm{CO}_{2}$ compensation point depends on temperature:

$$
\Gamma^{*}=c_{\Gamma} T_{\text {leaf }}
$$

where $c_{\Gamma}$ (1.7) determines the effect of leaf temperature on the $\mathrm{CO}_{2}$ compensation point. Dark respiration rate was estimated according to the $\mathrm{Q}_{10}$ rule:

$$
R_{\mathrm{d}_{-} \text {Tleaf }}=R_{\mathrm{d}}\left(25^{\circ} \mathrm{C}\right) Q_{10}^{\left[\left(\mathrm{T}_{\text {leaf }}-25\right) / 10\right]}
$$

where $R_{d}\left(25^{\circ} \mathrm{C}\right)$ is dark respiration at $25^{\circ} \mathrm{C}(0.66 \mu \mathrm{mol}$ $\mathrm{s}^{-1} \mathrm{~m}^{-2}$ ), and $\mathrm{Q}_{10}=2$.

\section{Canopy photosynthesis model}

Canopy photosynthesis is calculated by dividing the canopy into three layers and summing photosynthesis of those layers. Layer one consists of the upper part the of canopy, layer two includes the middle canopy leaves, layer three is the lower part of the canopy. There are two differences among the three layers: i) the light absorbed by the leaves; ii) the potential electron transport rate of the leaves.

The light absorbed by each layer $\mathrm{I}_{(\mathrm{i})}\left(\mu \mathrm{mol} \mathrm{s}^{-1} \mathrm{~m}^{-2}\right)$ is calculated using Beer-Lambert's Law (Kläring and Krumbein, 2013):

$I_{(i)}=\left(I_{\text {top }}+I_{\text {sun }}\right) k \mathrm{e}^{-k \frac{(2 i-1) L A I}{6}} \quad(i=1,3)$

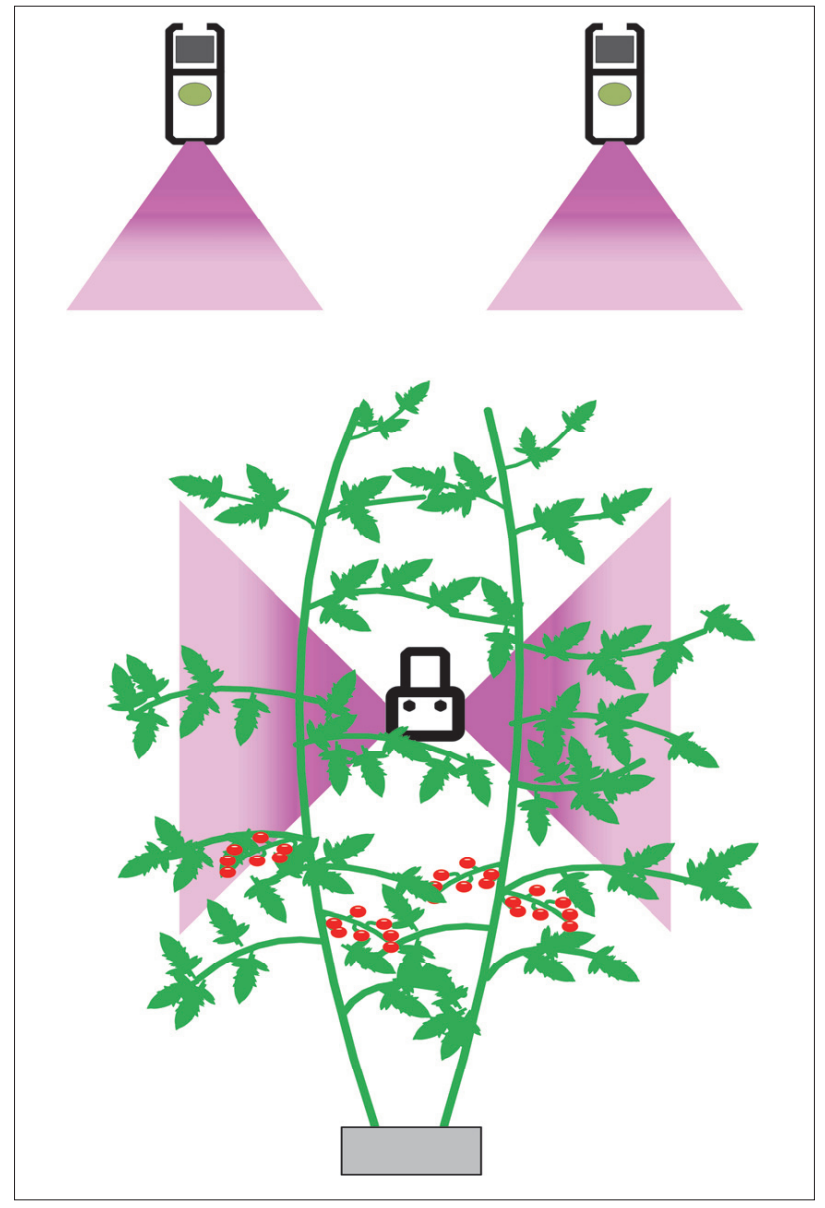

FIGURE 1. Profile of tomato canopy.

where i represents ith layer, $\mathrm{I}_{\text {top }}$ is top-lighting intensity above the canopy $\left(\mu \mathrm{mol} \mathrm{s}^{-1} \mathrm{~m}^{-2}\right), \mathrm{I}_{\text {sun }}$ is the sunlight intensity above the canopy $\left(\mu \mathrm{mol} \mathrm{s}^{-1} \mathrm{~m}^{-2}\right), \mathrm{k}$ is light extinction coefficient (0.7), and LAI is leaf area index $\left(3 \mathrm{~m}^{2} \mathrm{~m}^{-2}\right)$. In our simulation, strings with inter-lighting LED were mounted horizontally within each double row, placed in row direction and hang in the layer two (Figure 1). Since the total area of leaves illuminated by inter-lighting LEDs is relatively small, we assumed that light outputted by inter-lighting LEDs is distributed evenly in the layer two. The light absorbed by layer two $\mathrm{I}_{(2)}$ $\left(\mu \mathrm{mol} \mathrm{s}{ }^{-1} \mathrm{~m}^{-2}\right)$ is calculated as:

$$
I_{(2)}=\left(I_{\text {top }}+I_{\text {sun }}\right) k \mathrm{e}^{-k \frac{L A I}{2}}+\frac{3 I_{\text {inter }}}{L A I}
$$

where $\mathrm{I}_{\text {inter }}$ is the inter-lighting intensity $\left(\mu \mathrm{mol} \mathrm{s} \mathrm{m}^{-1} \mathrm{~m}^{-2}\right.$. The sunlight intensity above the canopy is calculated as:

$$
\mathrm{I}_{\text {sun }}=\tau_{\text {Gh }} \eta_{\text {Glob_PAR }} \mathrm{I}_{\text {Glob }}
$$

where $\tau_{\mathrm{Gh}}$ is the light transmission of the greenhouse cover (0.7), $\eta_{\text {Glob_PAR }}\left(2.3 \mu \mathrm{mol} \mathrm{J}^{-1}\right)$ is a conversion factor from global radiation to PAR and $\mathrm{I}_{\text {Glob }}\left(\mathrm{W} \mathrm{m}^{-2}\right)$ is the outdoor global radiation.

Various experiments have found that the potential electron transport rate $\left(\mathrm{J}_{\max }\right)$ of the upper canopy leaves is larger (Trouwborst et al., 2011). The $J_{\max }\left(25^{\circ} \mathrm{C}\right)$ of each layer in our model is different. For layer one, $\mathrm{J}_{\max }\left(25^{\circ} \mathrm{C}\right)=134 \mu \mathrm{mol}$ $\mathrm{s}^{-1} \mathrm{~m}^{-2}$. For layer two, $\mathrm{J}_{\max }\left(25^{\circ} \mathrm{C}\right)=92 \mu \mathrm{mol} \mathrm{s}^{-1} \mathrm{~m}^{-2}$. For layer three, $\mathrm{J}_{\max }\left(25^{\circ} \mathrm{C}\right)=65 \mu \mathrm{mol} \mathrm{s}^{-1} \mathrm{~m}^{-2}$. The canopy photosynthetic rate $\mathrm{P}_{\text {canopy }}\left(\mu \mathrm{mol} \mathrm{s}^{-1} \mathrm{~m}^{-2}\right)$ is given by: 


$$
\mathrm{P}_{\text {canopy }}=\sum_{\mathrm{i}=1}^{3} \frac{L A I}{3} P_{\text {leaf }}(i)
$$

where I represents ith layer, $\mathrm{P}_{\text {leaf }}(\mathrm{i})$ is the leaf photosynthetic rate of ith layer.

\section{Crop yield model}

The yield was determined by the partitioning of carbohydrate to fruits. By assuming that the tomato plants are fully generative, $74 \%$ of the carbohydrates was distributed to the fruits according to Heuvelink (1996). The fresh weight of fruits $\mathrm{Y}\left(\mathrm{kg} \mathrm{m}^{-2}\right)$ is calculated as:

$$
\mathrm{Y}=0.74 \eta_{\mathrm{DM}_{-} \mathrm{MM}} \mathrm{M}_{\mathrm{CH} 2 \mathrm{O}} \int_{t 0}^{t f} \mathrm{P}_{\text {canopy }} d t
$$

where $\eta_{\text {DM_FM }}\left(18.18 \times 10^{-3} \mathrm{~kg} \mathrm{~g}^{-1}\right)$ is the conversion factor from

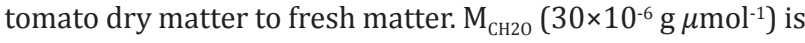
molar mass of carbohydrate, and $t 0$ and $t f$ are the beginning and the end of the predefined period.

\section{Objective function}

The objective function to be maximized is the expected economic benefit, described by:

$$
\mathrm{J}=q_{\text {Tom }}\left(Y_{\text {sl }}-Y_{\text {sun }}\right)-q_{e} \int_{t 0}^{t f}\left(\frac{I_{\text {top }}+I_{\text {inter }}}{\eta_{\text {photo }}}\right) d t
$$

where $Y_{\mathrm{sl}}\left(\mathrm{kg} \mathrm{m}^{-2}\right)$ is the crop yield with supplemental lighting, $Y_{\text {sun }}\left(\mathrm{kg} \mathrm{m}^{-2}\right)$ is the crop yield without supplemental lighting, $\mathrm{q}_{\text {Tom }}\left(\mathrm{CNY} \mathrm{kg}^{-1}\right)$ is the expected fruit price, $\mathrm{q}_{\mathrm{e}}\left(\mathrm{CNY} \mathrm{kWh}^{-1}\right)$ is electricity price, $\eta_{\text {photo }}\left(\mu \mathrm{mol} \mathrm{\textrm {J } ^ { - 1 }}\right)$ is photo efficiency of the supplemental lighting LED module.

\section{Dynamic light control algorithm}

The algorithm solves continuously for the top-lighting intensity and inter-lighting intensity that maximizes the objective function. In practice, the outdoor global radiation can be changed every 5-15 minutes. Considering practical implementation, the supplemental lighting intensity is changed once every 15 minutes. The algorithm can be divided into two steps:

Step (1): Input the expected fruit price $\mathrm{q}_{\mathrm{Tom}}$, electricity price $\mathrm{q}_{\mathrm{e}}$, and the installed capacity of the top-lighting and inter-lighting. Read temperature $\mathrm{T}_{\text {leaf }}, \mathrm{CO}_{2}$ concentration $\mathrm{CO}_{2 \mathrm{Air}}$, outdoor global radiation $\mathrm{I}_{\text {Glob }}$.

Step (2): Determine the optimal top-lighting intensity and inter-lighting intensity as follows:

a) Select an initial estimate $I_{\text {top }}$ and $I_{\text {inter }}$ of the optimal supplemental lighting intensity.

b) Calculate the economic benefit using Eq. (12).

c) Update the estimate of the optimal $I_{\text {top }}$ and $I_{\text {inter. }}$.

d) Stop the iteration when the maximum is located, otherwise go back to step (2).

The procedure for selecting iterative values of $I_{\text {top }}$ and $I_{\text {inter }}$ until the maximum economic benefit is reached, is solved by using the fmincon function in MATLAB's Optimization Toolbox.

\section{Simulation}

1. Data. The data is collected at a Venlo type greenhouse, Shanghai, China $\left(31^{\circ} 57^{\prime} \mathrm{N}, 121^{\circ} 70^{\prime} \mathrm{E}\right)$. The sensor data is collected every $5 \mathrm{~min}$, and is saved by a climate control computer (PRIVA). The simulation uses the indoor and outdoor climate data during the period of June 13, 2014 to July 12,
2014. The simulation is carried out for the following conditions: the expected fruit price ( $\left.8 \mathrm{CNY} \mathrm{kg}^{-1}\right)$, electricity price (0.617 CNY kWh-1).

2. Lighting regimes. Supplemental lighting sources are LEDs produced by Philips (Green Power LED Top-lighting module and Inter-lighting module). The installed capacity in top-lighting and inter-lighting is $95.2 \mathrm{~W} \mathrm{~m}^{-2}$ and $47.6 \mathrm{~W} \mathrm{~m}^{-2}$, respectively. The average photon efficiency of the supplemental lighting LED is $2.1 \mu \mathrm{mol} \mathrm{\textrm {J } ^ { - 1 }}$. The photoperiod is 14 hours (5:00 am to 19:00 pm).

Threshold control is conducted as a reference. The threshold values are adapted from Hovi-Pekkanen and Tahvonen (2008). The dynamic control can be divided into two types: dynamic on-off control and dynamic light control.

Threshold control (TSC): Top-lighting LEDs are turned off when outdoor global radiation exceeds $286 \mathrm{~W} \mathrm{~m}^{-2}$, inter-lighting LEDs are turned off when outdoor global radiation exceeds $572 \mathrm{~W} \mathrm{~m}^{-2}$.

Dynamic on-off control (DOC): top-lighting LEDs or inter-lighting LEDs are turned on at full power when the economic benefit of top-lighting or inter-lighting is greater than zero.

Dynamic light control (DLC): regulating the top-lighting intensity and the inter-lighting intensity continuously to maximize economic benefit.

\section{Results}

After thirty days, the threshold control (TSC) LEDs had the highest electricity consumption (45.14 $\mathrm{kWh} \mathrm{m}^{-2}$ ), followed by dynamic on-off control (DOC) LEDs (35.80 $\mathrm{kWh} \mathrm{m}^{-2}$ ) and dynamic light control (DLC) LEDs $(33.82$ $\mathrm{kWh} \mathrm{m}^{-2}$ ). The DOC LEDs consumed $20.69 \%$ less electricity than the TSC LEDs. However, there was no significant difference between the DOC LEDs and DLC LEDs in terms of the electricity consumption. The fresh fruit yield under natural light was lowest ( $5.71 \mathrm{~kg} \mathrm{~m}^{-2}$ ), supplemental lighting had improved the yield. TSC plants had the highest fresh fruit yield (10.08 $\left.\mathrm{kg} \mathrm{m}^{-2}\right)$, followed by DOC plants $\left(9.45 \mathrm{~kg} \mathrm{~m}^{-2}\right)$, and DLC plants $\left(9.32 \mathrm{~kg} \mathrm{~m}^{-2}\right)$. The fresh fruit yield of the TSC plants was approximately $6.6 \%$ higher than that of DOC and DLC plants. However, TSC plants had the lowest economic benefit (7.11 $\mathrm{CNY} \mathrm{m}^{-2}$ ) during the thirty days, followed by DOC plants (7.81 $\left.\mathrm{CNY} \mathrm{m}^{-2}\right)$, and DLC plants (8.06 CNY $\mathrm{m}^{-2}$ ).

As is shown in Figure 2, on two days $\left(27^{\text {th }}\right.$ of June and $28^{\text {th }}$ of June) the top-lighting electrical active power of TSC, DOC and DLC is similar. However, there was significant difference between the TSC and DOC in terms of the inter-lighting electrical active power. The DOC inter-lighting LEDs were turned off frequently. The TSC inter-lighting LEDs on the other hand were on because the outdoor global radiation was still below $572 \mathrm{~W} \mathrm{~m}^{-2}$. Therefore, at the end of the study, the total lighting time of TSC was greater than that of DOC. The difference in terms of electricity active power between DOC and DLC is very small. The DLC LEDs reduced the light intensity as soon as the outdoor global radiation increased, and increased the light intensity as soon as the outdoor global radiation decreased.

\section{Discussion}

The results suggest that there is a potential to increase economic benefit by optimizing top-lighting and inter-lighting. The data show that dynamic on-off control (DOC) and dynamic light control (DLC) had lower yield than threshold control (TSC). However, profit of DOC and DLC is higher than that of TSC because of lower electricity consumption. This 


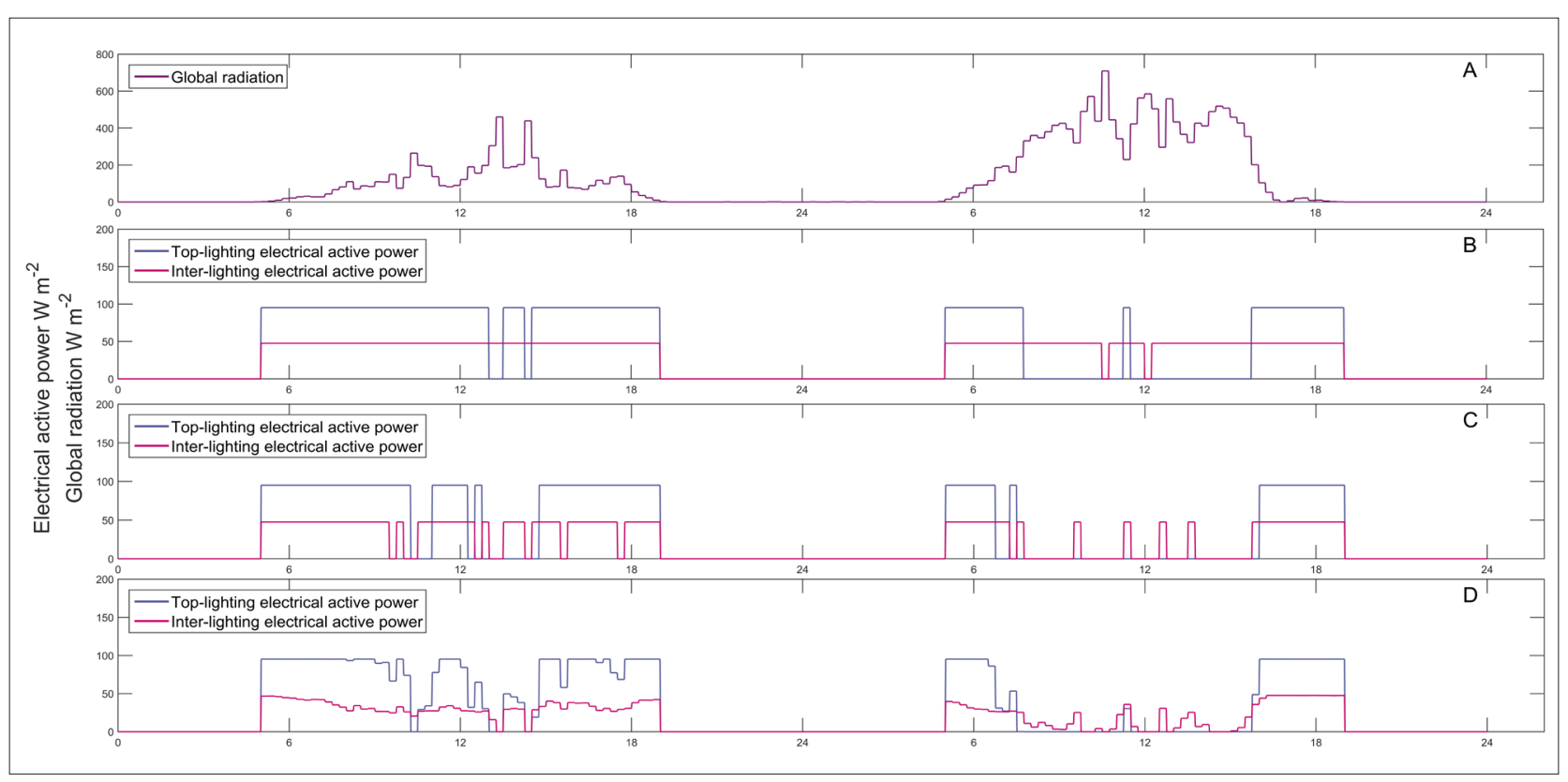

FiguRE 2. A) Global radiation; B) Electrical active power of threshold control (TSC); C) Electrical active power of dynamic onoff control (DOC); D) Electrical active power of dynamic light control (DLC) on $27^{\text {th }}$ and $28^{\text {th }}$ of June, 2014.

indicates the increased crop value sometimes may be insufficient to cover the cost of supplemental lighting in TSC.

One reason for the low profit of TSC is that expected fruit price is low in June. The low expected fruit price has great demands on the efficiency of supplemental lighting. However, threshold control does not consider this important factor. Another reason for the low profit of TSC is that the photosynthetic capacity of leaves in layer two is too low. The effect of supplemental lighting on photosynthesis is insignificant because these leaves are easier to be light-saturated. However, high threshold value (572 $\mathrm{W} \mathrm{m}^{-2}$ ) had kept the TSC inter-lighting LEDs on during the photoperiod. Therefore, the efficiency of TSC inter-lighting is low.

It must be noted that the less lighting time of inter-lighting may go against the original intent of inter-lighting. Previous studies have high threshold value or fixed time for inter-lighting. In addition, these studies have found that inter-lighting can increase the photosynthetic capacity of the lower leaves and improve the fruit quality. Our lighting time of inter-lighting is less than that of previous studies. Therefore, further researches are needed to quantify the influence of dynamic control of inter-lighting on the lower leaves.

Moreover, the data show that the difference between DOC and DLC in terms of economic benefit is small. This is because light intensity outputted by DOC LEDs is near the economic optimum light intensity so that the potential for improvement is limited. In addition, it is known that the efficiency of LEDs decreases when they are dimmed. Considering this deficiency, the slight advantage of the DLC may be negligible. However, this deficiency may be resolved with the development of LED technology in the future.

Current studies on supplemental lighting have mainly focused on investigating suitable light intensity, position and orientation to increase yield and improve quality. These researches have indeed promoted the development of supplemental lighting techniques. However, the electricity cost of supplemental lighting may prevent these techniques from being economically viable, because the main objective of supplemental lighting is to improve the economic benefit.
In our study, we mainly focus on optimizing supplemental lighting to maximize the economic benefit by means of finding a trade-off between the improvement of the yield and the cost. Based on a crop yield model and electricity cost of supplemental lighting, an economic benefit objective function was established, then two dynamic light control algorithms were proposed to optimize top-lighting and inter-lighting. The results show that these algorithms can effectively increase the economic benefit.

\section{Acknowledgments}

This work was financially supported by the National 863 High-Tech R\&D Program of China under Grant 2013AA103006 and the National Natural Science Foundation of China (Grant No. 61174090), and in part by the U.S. National Science Foundation's BEACON Center for the Study of Evolution in Action, under cooperative agreement DBI-0939454. We also thank the two anonymous reviewers for their valuable comments.

\section{References}

Bergstrand, K.-J., Suthaparan, A., Mortensen, L.M., and Gislerød, H.R. (2016). Photosynthesis in horticultural plants in relation to light quality and $\mathrm{CO}_{2}$ concentration. Europ. J. Hortic. Sci. 81(5), 237-242. https://doi.org/10.17660/eJHS.2016/81.5.1.

Farquhar, G.D., Von Caemmerer, S., and Berry, J.A. (1980). A biochemical model of photosynthetic $\mathrm{CO}_{2}$ assimilation in leaves of $\mathrm{C}_{3}$ species. Planta 149(1), 78-90. https://doi.org/10.1007/ BF00386231.

Guo, X., Hao, X., Khosla, S., Kumar, K.G.S., Cao, R., and Bennett, N. (2016). Effect of LED interlighting combined with overhead HPS light on fruit yield and quality of year-round sweet pepper in commercial greenhouse. Acta Hortic. 1134, 71-78. https://doi.org/10.17660/ ActaHortic.2016.1134.10.

Heuvelink, E. (1996). Tomato growth and yield: quantitative analysis and synthesis. Ph.D. thesis (Wageningen, the Netherlands: Wageningen UR), 326 pp. 
Heuvelink, E., and Challa, H. (1989). Dynamic optimization of artificial lighting in greenhouses. Acta Hortic. 260, 401-412. https:// doi.org/10.17660/ActaHortic.1989.260.26.

Heuvelink, E., Bakker, M.J., Hogendonk, L., Janse, J., Kaarsemaker, R., and Maaswinkel, R. (2006). Horticultural lighting in the Netherlands: New developments. Acta Hortic. 711, 25-33. https:// doi.org/10.17660/ActaHortic.2006.711.1.

Hogewoning, S.W., Trouwborst, G., Engbers, G.J., Harbinson, J., Van Ieperen, W., Ruijsch, J., Van Kooten, O., Schapendonk, A.H.C.M., and Pot, C.S. (2007). Plant physiological acclimation to irradiation by light-emitting diodes (LEDs). Acta Hortic. 761, 183-191. https://doi. org/10.17660/ActaHortic.2007.761.23.

Hovi-Pekkanen, T., and Tahvonen, R. (2008). Effects of interlighting on yield and external fruit quality in year-round cultivated cucumber Scientia Hortic. 116(2), 152-161. https://doi.org/10.1016/j. scienta.2007.11.010.

Jiang, C., Johkan, M., Hohjo, M., Tsukagoshi, S., Ebihara, M., Nakaminami, A., and Maruo, T. (2017). Photosynthesis, plant growth, and fruit production of single-truss tomato improves with supplemental lighting provided from underneath or within the inner canopy. Scientia Hortic. 222, 221-229. https://doi.org/10.1016/j. scienta.2017.04.026.

Kläring, H.-P., and Krumbein, A. (2013). The effect of constraining the intensity of solar radiation on the photosynthesis, growth, yield and product quality of tomato. J. Agron. Crop Sci. 199(5), 351-359. https://doi.org/10.1111/jac.12018.

Koivisto, A., and Hovi-Pekkanen, T. (2008). Interlighting in the production of greenhouse cucumber: economic comparison using the simulation model. Europ. J. Hortic. Sci. 73(4), 177-182. http:// www.pubhort.org/ejhs/2008/file_723266.pdf

Morrow, R.C. (2008). LED lighting in horticulture. HortScience 43(7), 1947-1950. https://doi.org/10.1007/978-981-10-5807-3_7.

Pepin, S., Fortier, E., Béchard-Dubé, S.A., Dorais, M., Ménard, C., and Bacon, R. (2014). Beneficial effects of using a 3-D LED interlighting system for organic greenhouse tomato grown in Canada under low natural light conditions. Acta Hortic. 1041, 239-246. https://doi. org/10.17660/ActaHortic.2014.1041.28.

Pinho, P., Hytönen, T., Rantanen, M., Elomaa, P., and Halonen, L. (2013). Dynamic control of supplemental lighting intensity in a greenhouse environment. Lighting Res. \& Technol. 45(3), 295-304. https://doi.org/10.1177/1477153512444064.

Schwend, T., Beck, M., Prucker, D., Peisl, S., and Mempel, H. (2016). Test of a PAR sensor-based, dynamic regulation of LED lighting in greenhouse cultivation of Helianthus annuus. Europ. J. Hortic. Sci. 81(3), 152-156. https://doi.org/10.17660/eJHS.2016/81.3.3.

Singh, D., Basu, C., Meinhardt-Wollweber, M., and Roth, B. (2015). LEDs for energy efficient greenhouse lighting. Renew. and Sustain. Energy Revs. 49, 139-147. https://doi.org/10.1016/j.rser.2015.04.117.

Tewolde, F.T., Lu, N., Shiina, K., Maruo, T., Takagaki, M., Kozai, T., and Yamori, W. (2016). Nighttime supplemental LED inter-lighting improves growth and yield of single-truss tomatoes by enhancing photosynthesis in both winter and summer. Frontiers in Plant Sci. 7, 1-10. https://doi.org/10.3389/fpls.2016.00448.

Trouwborst, G., Schapendonk, A.H.C.M., Rappoldt, K., Pot, S., Hogewoning, S.W., and Van Ieperen, W. (2011). The effect of intracanopy lighting on cucumber fruit yield-model analysis. Scientia Hortic. 129(2), 273-278. https://doi.org/10.1016/j. scienta.2011.03.042.

Van Iersel, M.W., and Gianino, D. (2017). An adaptive control approach for light-emitting diode lights can reduce the energy costs of supplemental lighting in greenhouses. HortScience 52(1), 72-77. https://doi.org/10.21273/HORTSCI11385-16.
Vanthoor, B.H.E., De Visser, P.H.B., Stanghellini, C., and Van Henten, E.J. (2011). A methodology for model-based greenhouse design, Part 2: Description and validation of a tomato yield model. Biosyst. Engin. 110(4), 378-395. https://doi.org/10.1016/j. biosystemseng.2011.08.005.

Received: Dec. 19, 2017

Accepted: Apr. 20, 2018

Addresses of authors:

Yuanxv Wang, Lihong $\mathrm{Xu}^{*}$ and Ruihua Wei

College of Electronics and Information Engineering, Tongji University, 4800 Cao An Highway, Jiading District, Shanghai, P.R. China

*Corresponding author; E-mail: xulhk@163.com 